\title{
Complex-Shaped Ceramic Composites Obtained by Machining Compact Polymer-Filler Mixtures
}

\author{
Rosa Maria da Rocha, ${ }^{\mathrm{a}, *}$, Peter Greil ${ }^{\mathrm{b}}$, José Carlos Bressiani ${ }^{\mathrm{a}}$, Ana Helena de Almeida Bressiani ${ }^{\mathrm{a}}$ \\ ${ }^{a}$ Instituto de Pesquisas Energéticas e Nucleares, IPEN CNEN/SP, Brazil \\ ${ }^{\mathrm{b}}$ Universtity of Erlangen-Nuernberg, Dept. Materials Science, Glass and Ceramics, Germany \\ ${ }^{\mathrm{c} C e n t r o}$ Técnico Aeroespacial, CTA-IAE, Brazil
}

Received: November 23, 2003; Revised: February 1, 2005

\begin{abstract}
Research in the preparation of ceramics from polymeric precursors is giving rise to increased interest in ceramic technology because it allows the use of several promising polymer forming techniques. In this work ceramic composite pieces were obtained by pyrolysis of a compacted mixture of a polysiloxane resin and alumina/ silicon powder. The mixture consists of $60 \mathrm{vol} \%$ of the polymer phase and $40 \mathrm{vol} \%$ of the filler in a 1:1 ratio for alumina/silicon, which was hot pressed to crosslink the polymer, thus forming a compact body. This green body was trimmed into different geometries and pyrolised in nitrogen atmosphere at temperatures up to $1600{ }^{\circ} \mathrm{C}$. X-ray diffraction analysis indicated the formation of phases such as mullite and $\mathrm{Si}_{2} \mathrm{ON}_{2}$ during pyrolysis, that result from reactions between fillers, polymer decomposition products and nitrogen atmosphere. The porosity was found to be less than $20 \%$ and the mass loss around $10 \%$. The complex geometry was maintained after pyrolysis and shrinkage was approximately $8 \%$, proving pyrolisis to be a suitable process to form near-net-shaped bulk ceramic components.
\end{abstract}

Keywords: polymer derevid ceramic, AFCOP, polymer precursor, composite

\section{Introduction}

One of the reasons for not using ceramic materials more frequently in industrial applications, besides their brittleness, may be found in machinability problems. Despite great improvements in sintering processes for ceramic parts, components for most applications still require finishing. Problems encountered in finishing high performance ceramics are caused precisely by its main attributes, as the high hardness of ceramics rapidly destroys the diamond tools that are used ${ }^{1}$.

An alternate way to overcome problems related to machinability in conventional ceramic processing has been the manufacture of complex shaped components from polymer-filler systems, followed by conversion to ceramic material through pyrolysis ${ }^{2-4}$. The advantages of this process are the relatively low processing temperatures, the possibility to incorporate fibrous and particulate reinforcement and low processing cost, besides the unique opportunity to make high quality ceramic components using plastic forming technologies ${ }^{5-7}$.

Processing of preceramic polymers into ceramic products involves shaping of a low viscous polymer precursor, subsequent curing, and pyrolysis at temperatures above $800{ }^{\circ} \mathrm{C}$. Due to the marked density difference between the polymer $\left(1-1.2 \mathrm{~g} . \mathrm{cm}^{-1}\right)$ and the ceramic phases (2-3 g.cm $\left.{ }^{-1}\right)$, linear shrinkage of more than $30 \%$ usually results in extensive cracking and porosity. To overcome this problem, a modified process, the so called AFCOP (active filler controlled polymer pyrolysis) was developed by Greil ${ }^{8}$. According to this method, the polymer is partially filled with inert or active powder particles, typically in the range of $30-50$ vol\%, to reduce shrinkage and to enable the manufacture of bulk crack-free ceramics.

When inert fillers such as $\mathrm{Al}_{2} \mathrm{O}_{3}, \mathrm{SiC}, \mathrm{B}_{4} \mathrm{C}, \mathrm{Si}_{3} \mathrm{~N}_{4}$, etc, are used, the precursor volume is reduced and this lowers linear shrinkage of the sample. However, active fillers like $\mathrm{Ti}, \mathrm{Nb}, \mathrm{Cr}, \mathrm{Mo}, \mathrm{B}, \mathrm{MoSi}_{2}$ can lower the shrinkage caused during polymer to ceramic conversion by reacting with the solid, and gaseous decomposition products of the polymer precursor and/or the firing atmosphere to form carbides, oxides, nitrides or mixtures ${ }^{9-11}$. This reaction can in fact occur with expansion of the filler particles, which counteracts the shrinkage during densification, and lead to near-net-shaped ceramic components.

Typical grain sizes of the active filler powders are in the range of 1 to $10 \mu \mathrm{m}$, and part of this can be replaced by inert filler powders. The inert filler particles are used to stabilize a homogeneous distribution of the active filler phase particles, by reducing sedimentation effects during processing. A number of systems have already been investigated using polysiloxane resins as preceramic polymers filled with different oxide, carbide or metallic powders ${ }^{9-12}$. This work reports data about samples obtained by mixing $\mathrm{Al}_{2} \mathrm{O}_{3}$ as inert filler, $\mathrm{Si}$ as active filler and a commercially available polysiloxane resin PMS - $\left(\mathrm{CH}_{3} \mathrm{SiO}_{15}\right)_{\mathrm{n}}$. A homogeneous mixture of $40 \mathrm{vol} \%$ of the total filler powder in the ratio of $1: 1$, in the polymer matrix (dissolved in a suitable solvent) was obtained and used to prepare compacted bodies that could be easily cut, drilled and machined before pyrolysis in a nitrogen atmosphere. These materials can be molded into complex geometries, making it a suitable process to form near-net-shaped bulk ceramic composites.

\section{Experimental Procedure}

A commercially available thermosetting solid poly(methylsiloxane) (PMS-MK, Wacker AG, Burghausen, Germany) with a general formula $\left(\mathrm{CH}_{3} \mathrm{SiO}_{1.5}\right)_{\mathrm{n}}$, with $\mathrm{n}=130-150$ was used as a preceramic binder precursor. The polymer is a powder at room temperature and has a melting point of $42{ }^{\circ} \mathrm{C}$. The total carbon content is up to $13.2 \mathrm{wt}$. (\%). The average molecular weight is $9400 \mathrm{~g} \cdot \mathrm{mol}^{-1}$ and the density, in the range of 1.1-1.3 g.cm $\mathrm{cm}^{-3}$. The amount of cross-linking active hydroxyl- $(-\mathrm{Si}-\mathrm{OH})$ and ethoxy- $\left(-\mathrm{Si}_{-}-\mathrm{OC}_{2} \mathrm{H}_{5}\right)$ groups is $4 \mathrm{~mol} \%$. Due to the release of water and ethanol upon polycondensation of (-Si-OH) and $\left(-\mathrm{Si}-\mathrm{OC}_{2} \mathrm{H}_{5}\right)$ groups, curing has to be done under pressure and at temperatures between $150-250{ }^{\circ} \mathrm{C}$.

Silicon ( $\mathrm{Si}$ ) powder, used as an active filler, with a mean particle 
size of $8.8 \mu \mathrm{m}$ was mixed with $\alpha-\mathrm{Al}_{2} \mathrm{O}_{3}$ (A-16 SG, Alcoa) powder (an inert filler) with a mean particle size of $0.9 \mu \mathrm{m}$, as measured by the laser scattering method. Specimens were prepared with solid PMS polymer phase by adding $40 \mathrm{vol} \%$ of filler powder. The ratio of active filler $(\mathrm{Si})$ to inert filler $\left(\mathrm{Al}_{2} \mathrm{O}_{3}\right)$ was set at 1:1.

Powders were mixed with a solvent (acetone), forming a highly viscous slurry, and homogenized by mechanical and ultrasonic stirring. After removing the solvent by heating on a hot plate fitted with a magnetic stirrer, the mixture was dried at $45{ }^{\circ} \mathrm{C}$ for 12 hours and then milled and sieved $(150 \mu \mathrm{m})$ to render a fine powder. Cylindrical specimens $30 \mathrm{~mm}$ in diameter were compacted by uniaxial hot pressing with a pressure of $40 \mathrm{MPa}$ at $170{ }^{\circ} \mathrm{C}$ for 30 minutes. During hot pressing, curing of poly(methylsiloxane) via polycondensation resulted in an unmeltable thermoset. Aluminun acetylacetonate $\left(\mathrm{AlO}_{6} \mathrm{C}_{15} \mathrm{H}_{21}\right)$ was added as a curing catalyst $(0.1 \text { wt. }(\%))^{10,12,13}$. The compacted specimens were then cut, drilled and machined into complex shapes followed by pyrolysis in an electrically heated tube furnace, in a nitrogen atmosphere. A typical heating cycle consisted of heating up to $500{ }^{\circ} \mathrm{C}$ at $5{ }^{\circ} \mathrm{C} / \mathrm{min}$, holding at this temperature for 4 hours; heating again at $3{ }^{\circ} \mathrm{C} / \mathrm{min}$ up to three different final temperatures of $1450{ }^{\circ} \mathrm{C}$ for 2 hours, $1500{ }^{\circ} \mathrm{C}$ for 2 hours and $1600{ }^{\circ} \mathrm{C}$ for 1 hours, and cooling at $10{ }^{\circ} \mathrm{C} / \mathrm{min}$.

Thermogravimetric analysis (TGA) of the green body was carried out in a thermobalance (Perkin Elmer model-TGA-7), in flowing nitrogen with a heating rate of $10{ }^{\circ} \mathrm{C} / \mathrm{min}$ up to a maximum temperature of $1000{ }^{\circ} \mathrm{C}$. The bulk density of the pyrolysed samples was measured by the Archimedes method, using distilled water. The open porosity was determined by measuring the volume of absorbed water. Weight and linear dimensional variations were measured by weighing and measuring the dimensions of the samples before and after pyrolysis respectively. Phase analysis of the crystalline constituents was done by X-ray diffraction analysis using monochromated $\mathrm{CuK} \alpha$-radiation (Philips-model PW18/30). The microstructure of the pyrolysed material was examined by optical microscopy (Leica-model DMRXP) and by scanning electron microscopy (SEM) (Zeiss model-LEO $435 \mathrm{Pi}$ ) equipped with energy dispersive spectroscopy (EDS) for element mapping.

\section{Results and Discussion}

The green bodies produced from the mixture of polysiloxane and filler powders were compact and withstood machining and drilling, without change in shape after pyrolysis, and were visually crack free (Figure 1).
The green density of the hot pressed samples was $2.03 \pm 0.02 \mathrm{~g} / \mathrm{cm}^{3}$. This value corresponds to total densification of the mixture according to theoretical density calculated by the mixtures rule, and for which the theoretical density of polysiloxane was considered to be $1.3 \mathrm{~g} . \mathrm{cm}^{-3}$. This value confirms that polysiloxane resin melted and wetted the filler particles during hot pressing, imparting good strength to the body to enable machining without damage or cracking.

Figure 2 shows the TGA curve of the polymer-filler mixture and reveals at least two chemically distinct weight loss events. The first one, in the range of $300-600{ }^{\circ} \mathrm{C}$, probably corresponds to release of some cure products not eliminated during cross-linking and also to the evolution of organic phases of $\mathrm{CH}_{4}$ and $\mathrm{C}_{2} \mathrm{H}_{4}$ usually observed in silicones or its products. The decomposition of the polysiloxane matrix results in the higher weight loss at around $600{ }^{\circ} \mathrm{C}$, due to evolution of cleavage of $\mathrm{Si}-\left(\mathrm{CH}_{3}\right)$ and redistribution reactions between $\mathrm{Si}-\mathrm{O}$ and $\mathrm{Si}-\mathrm{C}$ bonds ${ }^{14}$. The organic-inorganic conversion, with the formation of the SiOC glass, occurs between 700 and $900{ }^{\circ} \mathrm{C}$ and corresponds to the mineralization process of the material. The total weight loss between room temperature and $1000{ }^{\circ} \mathrm{C}$ is $4.5 \%$.

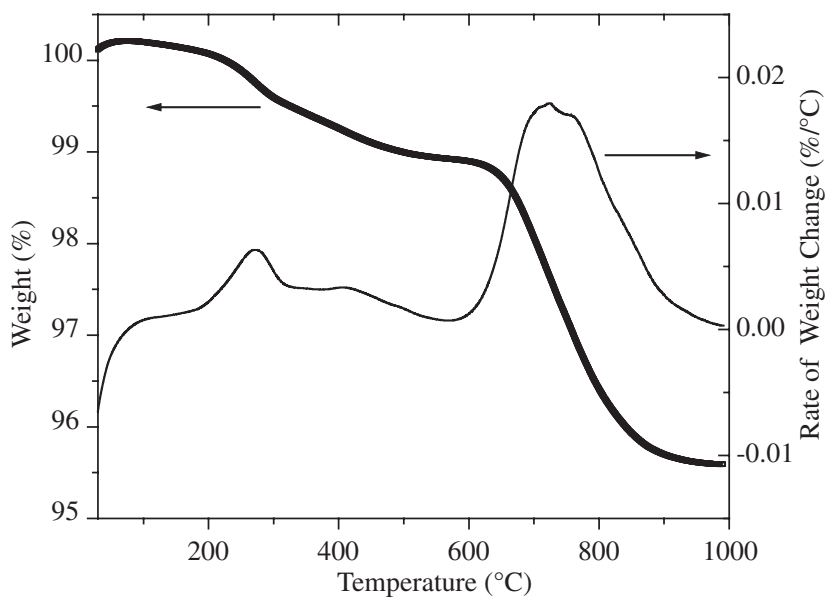

Figure 2. TGA curve and the corresponding rate of weight change curve of the polymer-filler mixture at a constant heating rate of $10{ }^{\circ} \mathrm{C} \mathrm{min}-1$ in $\mathrm{N}_{2}$ atmosphere.
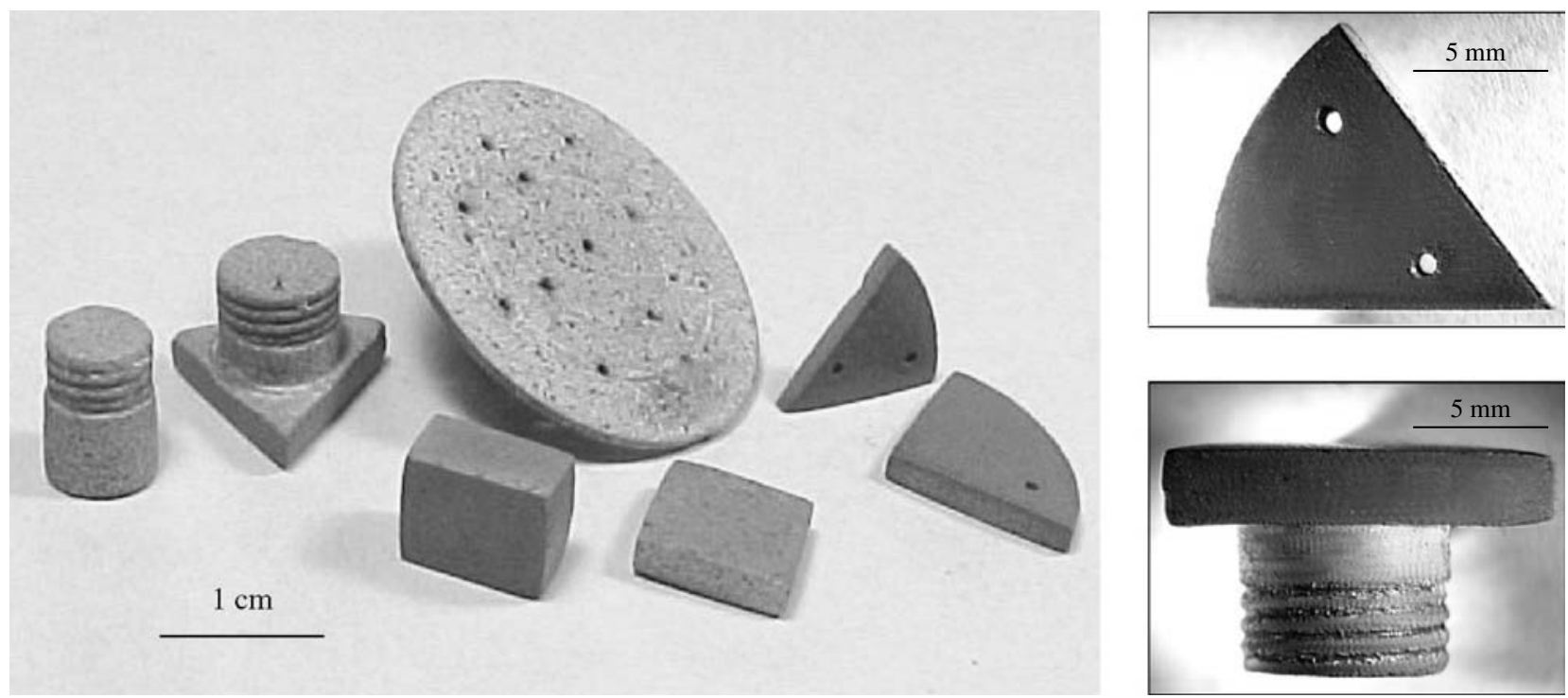

Figure 1. Samples obtained from the AFCOP. Samples were cut, drilled, machined and then pyrolysed at $1500^{\circ} \mathrm{C} / 2 \mathrm{~h}$. 
Table 1 lists density, porosity, weight and linear dimensional change after pyrolysis during the three different heat treatments. The porosity is relatively high compared to ceramics obtained by sintering of powders, even in samples pyrolysed at $1600{ }^{\circ} \mathrm{C}$. The apparent density decreases as temperature increases, due probably to increase in weight loss caused by carbothermal reduction of $\mathrm{SiO}_{2}$. This reaction leads to gaseous species, $\mathrm{SiO}$ and $\mathrm{CO}$ which may form in the Si-O-C system at higher temperatures $\left(>1400{ }^{\circ} \mathrm{C}\right)^{13}$. The total linear shrinkage is less $(\approx 8 \%)$ than that typically observed in conventional sintering processes (15 to $20 \%)^{15}$.

Polished surfaces of pyrolysed samples were observed by optical microscopy (Figure 3). The silicon filler distribution can be easily observed owing to contrast at low magnifications (100x). The highest concentration of silicon (bright phase) was observed in the sample pyrolysed at $1450{ }^{\circ} \mathrm{C} / 2 \mathrm{~h}$, and it decreased as pyrolysis temperature increases.

Reactions between the polysiloxane, fillers and $\mathrm{N}_{2}$ atmosphere during pyrolysis take place giving rise to what appears to be different ceramic phases. The green body, which is initially a mixture of metal, polymer and ceramic, converts gradually to a multiphase ceramic compound upon thermal treatment. The phases resulting from pyrolysis were identified from X-ray diffraction patterns and the phase development at different temperatures is shown in Figure 4. After 2 hours at $1450{ }^{\circ} \mathrm{C}$ un-reacted $\mathrm{Si}$ is still present. This result is in agreement with the optical microscopic observations which revealed more metallic phases in the sample pyrolysed at this temperature. Covalent phases, $\mathrm{Si}_{2} \mathrm{ON}_{2}$ and $\mathrm{SiAlON}$, resulting from reactions between $\mathrm{Si}, \mathrm{N}_{2}, \mathrm{Al}_{2} \mathrm{O}_{3}$ and the polymer residue were also identified and $\beta$-SiC is present even in the sample pyrolysed at the lowest temperature. $\mathrm{Al}_{2} \mathrm{O}_{3}$ was also detected at all temperatures, although the intensities of the peaks decreased with increase in temperature. On the other hand, mullite phase and SiAlON phases (X-SiAlON, $\beta$-SiAlON and $\mathrm{O}$ '-SiAlON) formed as the temperature increased.

These different phases are distributed in the ceramic body according to the initial distribution in the green compact sample. Finer the initial powder and its homogeneity, more homogeneous was the final multiphase distribution. Elemental analysis with energy dispersive spectroscopy (EDS) during SEM observation of polished surfaces of pyrolysed samples was used to distinguish the phases. Figure 5 shows a micrograph obtained using back-scattered electrons and contrast to visualize the different phases in the sample according to atomic number of the predominant element present in the phase. The bright spot in the micrograph was identified as Si by EDS, as shown in spectrum 1 (Figure 5). Around this particle, besides Si, the elements $\mathrm{O}$ and $\mathrm{Al}$ were also detected (spectrum 2). This phase could be a mullite phase $\left(\mathrm{Al}_{6} \mathrm{Si}_{2} \mathrm{O}_{13}\right)$ that formed by reaction between $\mathrm{Al}_{2} \mathrm{O}_{3}$ filler and the $\mathrm{SiO}_{2}$ layer that resulted from the oxidation of Si particle or from the polymer decomposition. EDS number 3 corresponds to a region of the $\mathrm{Al}_{2} \mathrm{O}_{3}$ particle.

Figure 6 shows another micrograph obtained with back scattered electrons, of the sample pyrolysed at $1600^{\circ} \mathrm{C}$. The bright spots related to pure $\mathrm{Si}$ are not observed in this sample, indicating that all $\mathrm{Si}$ had reacted to form $\mathrm{Si}_{2} \mathrm{ON}_{2}, \beta$ - SiC, mullite or $\mathrm{SiO}$ gas phase. Three dif-

Table 1. Density, open porosity, weight and linear dimensional change of samples pyrolysed at the three different temperatures.

\begin{tabular}{lcccc}
\hline Temperature & $\begin{array}{c}\text { Density } \\
\left(\mathrm{g} / \mathrm{cm}^{3}\right)\end{array}$ & $\begin{array}{c}\text { Porosity } \\
(\%)\end{array}$ & $\begin{array}{c}\text { Weight } \\
\text { change } \\
(\%)\end{array}$ & $\begin{array}{c}\text { Linear } \\
\text { change }(\%)\end{array}$ \\
\hline $1450{ }^{\circ} \mathrm{C} / 2 \mathrm{~h}$ & $2.50 \pm 0.04$ & $17.4 \pm 0.8$ & $-10.3 \pm 0.7$ & $-7.8 \pm 0.5$ \\
$1500{ }^{\circ} \mathrm{C} / 2 \mathrm{~h}$ & $2.47 \pm 0.02$ & $17.7 \pm 0.9$ & $-11.6 \pm 0.8$ & $-8.0 \pm 0.6$ \\
$1600{ }^{\circ} \mathrm{C} / 1 \mathrm{~h}$ & $2.41 \pm 0.03$ & $19.5 \pm 0.7$ & $-11.4 \pm 0.6$ & $-8.2 \pm 0.7$ \\
\hline
\end{tabular}

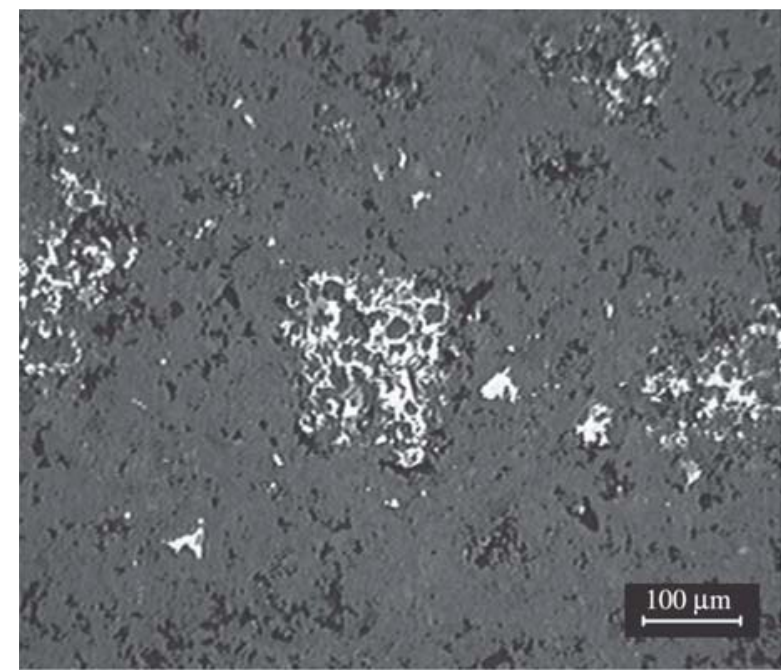

(a)

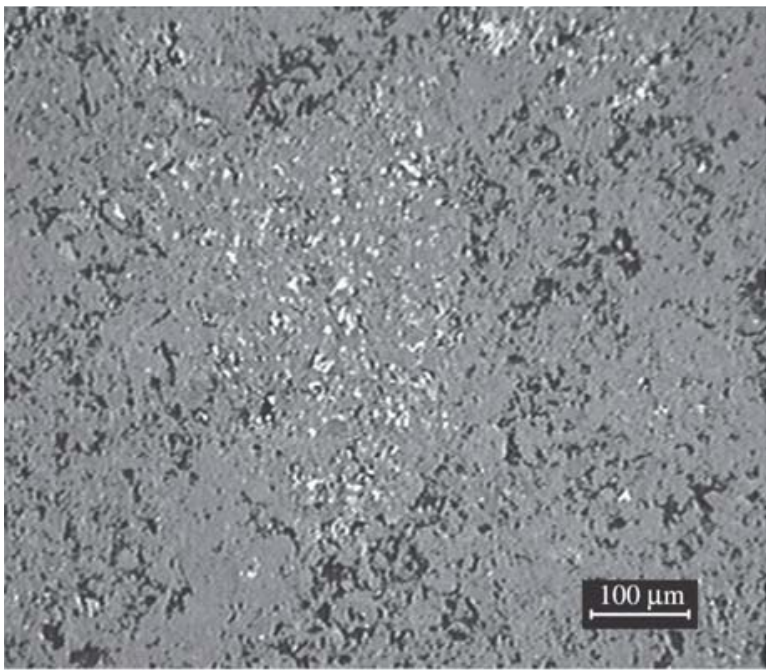

(b)

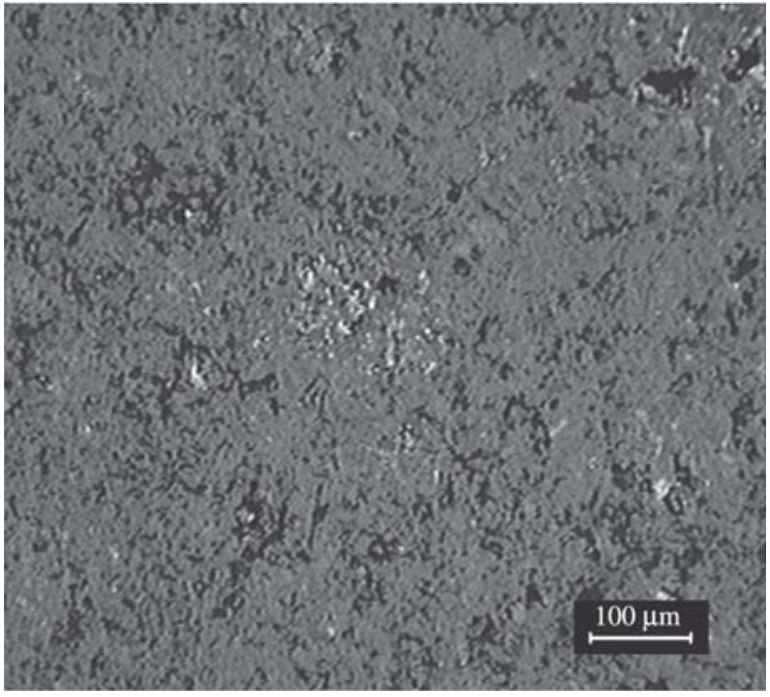

(c)

Figure 3. Optical micrographs of the polished surface after pyrolysis at: a) $1450{ }^{\circ} \mathrm{C} / 2 \mathrm{~h}$; b) $1500{ }^{\circ} \mathrm{C} / 2 \mathrm{~h}$; c) $1600{ }^{\circ} \mathrm{C} / 1 \mathrm{~h}$. 
ferent regions were examined by EDS showing distinct phases. These phases were identified as $\beta$ - SiC, mullite and SiAlON, according to elemental concentrations.

SEM examination of fracture surfaces of pyrolysed samples show clear evidence of large pores and the presence of structures like

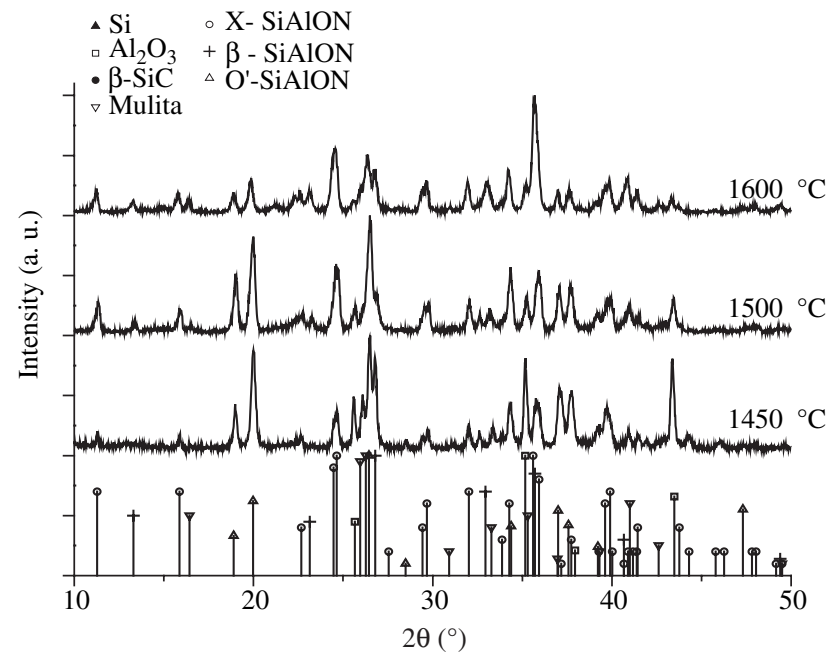

Figure 4. X-ray diffraction patterns of specimens after pyrolysis at three different final temperatures. whiskers and elongated grains (Figure 7). These structures could be observed inside the large pores and channels.

The micro-hardness of the resulting multiphase compound after pyrolysis was determined by Vickers indentation using a load of $4.5 \mathrm{~N}$.

The average value of 20 measurements was $8.6 \pm 1.8 \mathrm{GPa}$. This value is relatively low and presents a large dispersion because of porosity, difficulty in obtaining a good smooth surface for indentation and also the presence of different phases in the sample. Figure 8 shows an optical micrograph of the indentation on the polished surface (Figure 8a) and a micrograph at higher magnification with an indentation in a region with a mixture of phases (Figure $8 b$ ).

\section{Conclusions}

In this investigation the AFCOP process method has been successfully applied to a system of inert filler $\left(\mathrm{Al}_{2} \mathrm{O}_{3}\right)$ and active filler (Si) for the preparation of multiphase ceramic compound pieces. The ceramic bodies present shape retention and very low linear shrinkage (8\%), compared to those produced by conventional ceramic sintering. Therefore this is a suitable process to form near-net-shaped bulk ceramic components. The major phases formed upon pyrolysis were covalent ceramic materials like $\mathrm{Si}_{2} \mathrm{ON}_{2}, \mathrm{SiAlONs}$ phases and $\beta$-SiC that guarantee refractory performance. The material had relatively high porosity $(\sim 20 \%)$ and low Vickers hardness ( $\sim 8.6 \mathrm{GPa})$. These results, besides the lack of homogeneity, are some of the drawbacks to overcome, to improve mechanical properties for widespread application of this process to obtain complex shaped ceramic bodies.
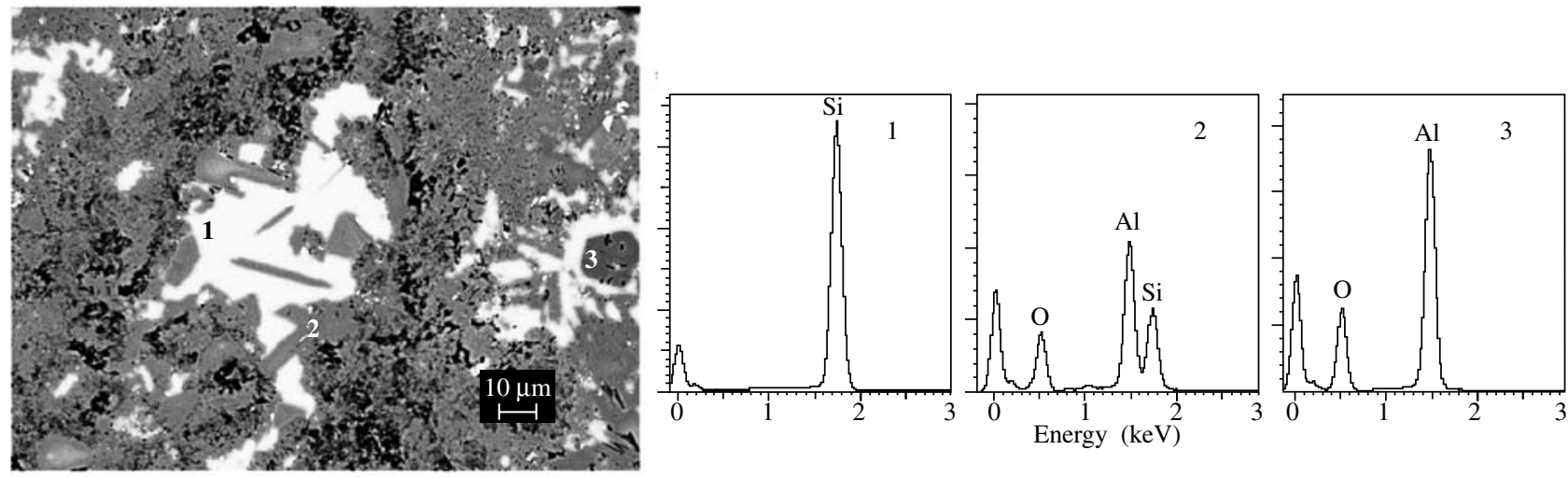

Figure 5. SEM micrograph of the sample pyrolysed at $1450{ }^{\circ} \mathrm{C} / 2 \mathrm{~h}$ using back scattered electrons showing $\mathrm{Si}$ particles embedded in a $\mathrm{Si}, \mathrm{Al}, \mathrm{O}$ matrix, as determined by EDS.
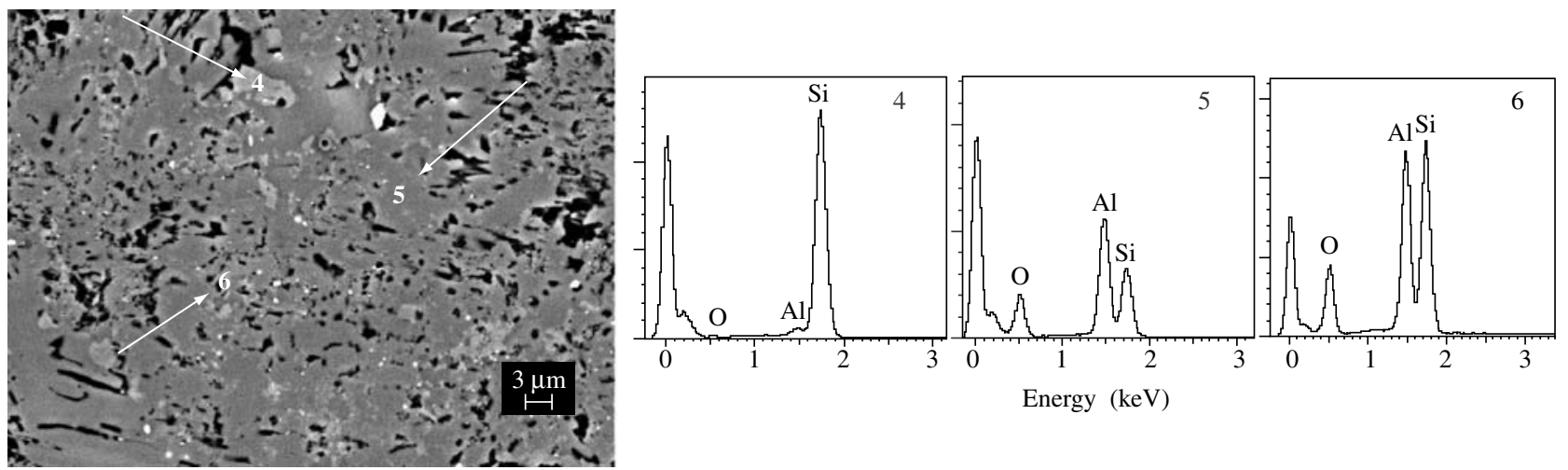

Figure 6. SEM micrograph of the sample pyrolysed at $1600{ }^{\circ} \mathrm{C} / 1 \mathrm{~h}$ using back scattered electrons showing regions with differences in elemental composition, according to the EDS. 


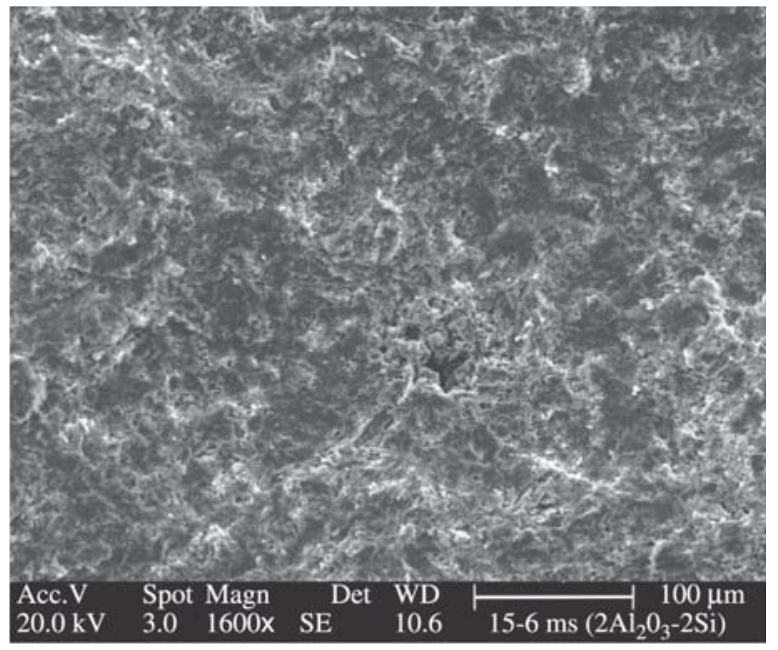

(a)

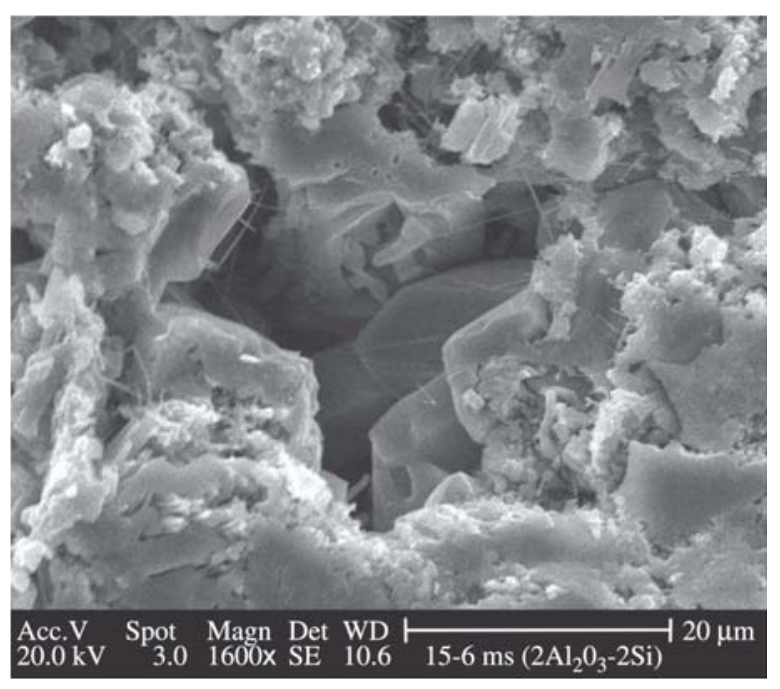

(b)

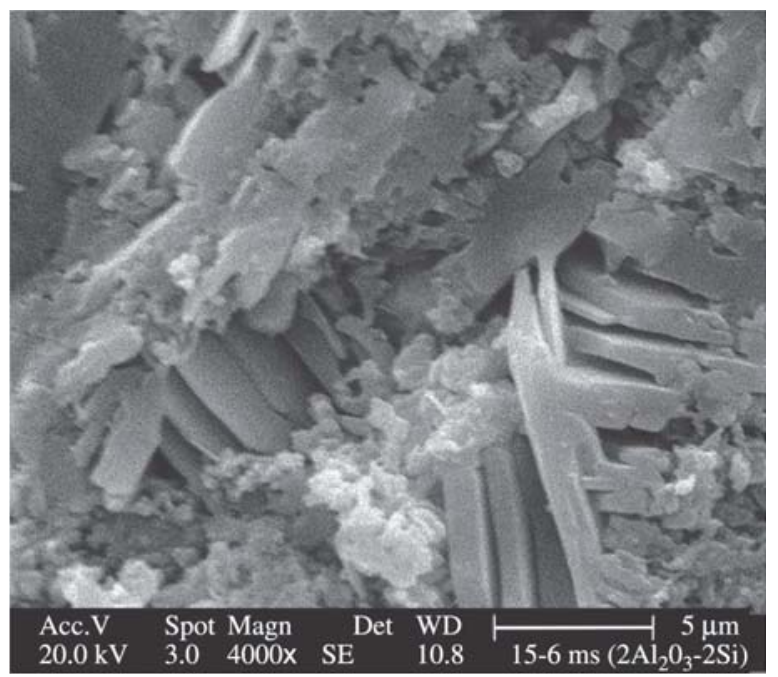

(c)

Figure 7. SEM micrographs of the fracture surface of the sample pyrolysed at $1500{ }^{\circ} \mathrm{C} / 2 \mathrm{~h}$ : a) general image; b) and c) details inside the pores.
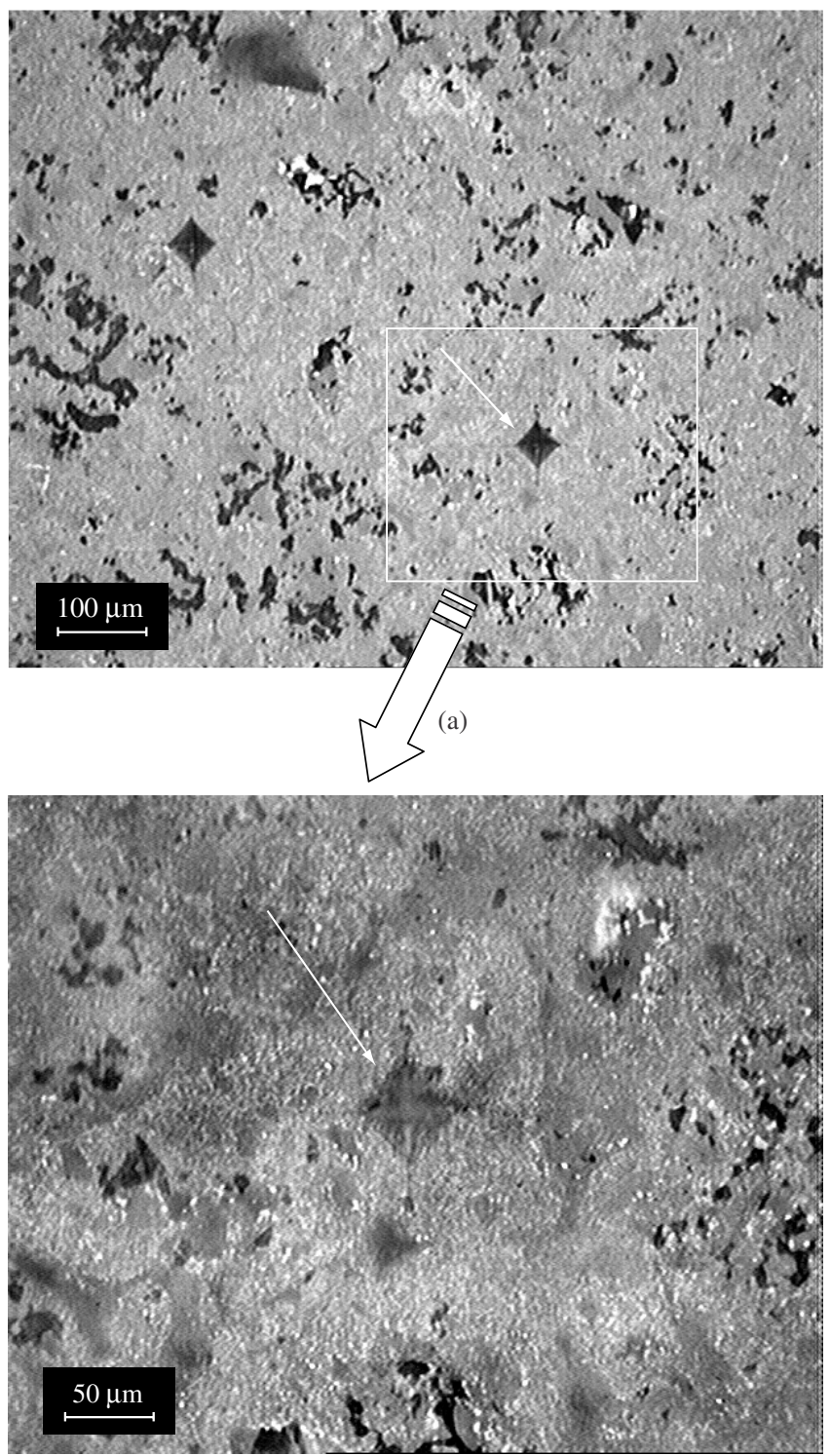

(b)

Figure 8. Optical micrographs of the polished surface of the sample pyrolysed at $1600{ }^{\circ} \mathrm{C} / 1 \mathrm{~h}$ : a) showing Vickers indentations; b) indentation in a region with a mixture of phases.

\section{Acknowledgments}

The authors gratefully acknowledge the financial support of Fapesp, Probral and CNPq (Brazil).

\section{References}

1. König W, Verlemann E. Machining Advanced Ceramics- A Challenge in Production Technologoy- In: Davidge RW, Van de Voorde WH, editor. Design with Structural Ceramics. London: Elsevier; 1991.

2. Greil P. Near Net Shape Manufacturing of Polymer Derived Ceramics. Journal of the European Ceramic Society. 1998; 18(13):1905-1914.

3. Walter S, Suttor D, Erny T, Hahn B, Greil P. Injection Moulding of Polysiloxane/Filler Mixtures for Oxycarbide Ceramic Composites. Journal of the American Ceramic Soiety. 1996; 16(4):387-393.

4. Suttor D, Kleebe HJ, Ziegler G. Synthetic low-shrinkage oxide-matrices from filled polymeric siloxanes. Ceramic Engineering Science Processing. 1997; 17(4):27-35.

5. Rice RW. Ceramic from Polymer Pyrolysis, Opportunities and Needs- 
A Materials Perspective. American Ceramic Society Bulletin. 1983; 62(8):889-892.

6. Bill J, Wakai F, Aldinger F. Precursor-Derived Ceramics-Synthesis, Structures and High Temperature Mechanical Properties. Weinheeim, Germany: Wiley-VCH; 1999.

7. Kohyama A, Katani M, Katoh Y, Nakayasu T, Sato M, Yamamura T, Okamura K. High-perfomance $\mathrm{SiC} / \mathrm{SiC}$ composites by improved PIP processing with new precursor polymers. Journal of Nuclear Materials. 2000; 283-287:565-569.

8. Greil P. Active-filler-controlled pyrolysis of preceramic polymers. Journal of the American Ceramic Society. 1995; 78(4):835-848.

9. Kaindl A, Lehner W, Greil P, Kim DJ. Polymer-filler derived $\mathrm{Mo}_{2} \mathrm{C}$ Ceramics. Materials Science Engineering. 1999; A260(1-2):101-107.

10. Dernovsek O, Bressiani JC, Bressiani AHA, Acchar W, Greil P. Reaction Bonded Niobium carbide Ceramics from polymer-filler mixtures. Journal of Materials Science. 2000; 35(9):2201-2207.
11. Michalet T, Parlier M, Addad A, Duclos R. Formation at low temperature with low shrinkage of polymer/ $/ \mathrm{Al} / \mathrm{Al}_{2} \mathrm{O}_{3}$ derived mullite. Ceramic. International. 2001; 27(3):315-319.

12. Melcher R, Cromme P, Scheffler M, Greil P. Centrifugal Casting of thin-walled Ceramic Tubes from Preceramic Polymers. Journal of the American Ceramic Soiety. 2003; 86(7):1211-1213.

13. We Q, Pippel E, Woltersdorf J, Scheffler M, Greil P. Interfacial SiC formation in polysiloxane-derive Si-O-C ceramics. Journal of Material Chemistryl Physics. 2002; 73(2-3):281-289.

14. Belot V, Corriu RJP, Leclercq D, Mutin PH, Vioux A. Thermal redistribuition reactions in crosslinked polysiloxanes. Journal of Polymer Science: Part A. 1992; 30(4):613-623.

15. Marchi J, Bressiani AHA, Bressiani JC. Densification studies of silicon carbide based ceramics with yttria, silica and alumina as additives. Materials Research. 2001; 4(4):231-236. 